How Bad is Corruption?

Cross-country Evidence of the Impact of Corruption on Economic Prosperity

Bentzen, Jeanet Sinding

Published in:

Review of Development Economics

DOI:

10.1111/j.1467-9361.2011.00653.x

Publication date:

2012

Document version

Early version, also known as pre-print

Citation for published version (APA):

Bentzen, J. S. (2012). How Bad is Corruption? Cross-country Evidence of the Impact of Corruption on Economic Prosperity. Review of Development Economics, 16(1), 164-187. https://doi.org/10.1111/j.1467-

9361.2011.00653.x 


\title{
How Bad is Corruption? Cross-country Evidence of the Impact of Corruption on Economic Prosperity
}

\author{
Jeanet Sinding Bentzen*
}

\begin{abstract}
Most people today would argue that corruption is bad for countries' economic development. Yet, we still lack a reliable empirical estimate of the effect. This study addresses the econometric shortcomings of the literature and provides an estimate of the causal impact of corruption on gross domestic product per capita across countries. Certain dimensions of a country's culture are used as instruments for corruption. These instruments stay strong when the other deep determinants of economic development, geography, and the remaining dimensions of institutions and culture are controlled for. In the process of choosing controls, however, the entire set of variables available in the Quality of Governance online database (QOG) that includes all central variables from the literature on institutions and culture are included. It is found that corruption does exert a significant and negative impact on countries' productivity levels.
\end{abstract}

\section{Introduction}

Most of us agree that corruption is a government failure that one would like to eliminate (see Leff (1964) for a counter argument), but how bad is it really? It is important to get a sense of the severity of the problem in order to be able to prioritize which government inefficiencies to fight first. Mauro (1995) provided an empirical estimate of the impact of corruption on investments and growth. Using the instrument variables approach, he aimed at solving the obvious endogeneity issues: Not only does economic performance influence corruption, but countries performing better might also have more resources to combat corruption. Also, other factors might influence both corruption and economic performance. Mauro found that corruption reduces investments and thereby economic growth. However, Mauro's study has two econometric shortcomings that the present paper tries to deal with.

Mauro's instrument for corruption was ethnolinguistic fractionalization (ELF). The idea is that bureaucrats may favor members of their own ethnolinguistic group and corruption is expected to be higher the higher the degree of ELF in a country. However, the assumption of exclusion restrictions does not hold: ELF might be correlated with other determinants of growth that are excluded from the analysis (Acemoglu et al., 2001). For instance, Easterly and Levine (1997) argued that ELF can influence performance by creating political instability. La Porta et al. (1999) showed that countries closer to the equator are more ethnolinguistically fractionalized than countries further away. If, for example, political instability and distance to the equator influence growth, ELF is an invalid instrument. Indeed, it seems that these factors do influence growth (Easterly and Levine, 1997; Gallup et al., 1999; Sachs, 2003).

\footnotetext{
* Bentzen: University of Copenhagen, Øster Farimagsgade 5, building 26, 1353 Copenhagen K, Denmark. Tel: +45-35324400; E-mail: Jeanet.Bentzen@econ.ku.dk. The author thanks Thomas Barnebeck Andersen, Christian Sinding Bentzen, Carl-Johan Dalgaard, Joannes Jacobsen, Peter Norman Sørensen, an anononymous referee, and seminar participants at PhD seminars at the Department of Economics, University of Copenhagen for useful comments and suggestions. Errors are those of the author.
} 
To alleviate this problem, one could include controls for geography and political instability in Mauro's regressions. The second econometric problem then arises, however: ELF becomes a weak instrument when including other determinants of economic outcomes in Mauro's regressions.

These issues are addressed by providing new instruments for corruption, namely cultural values of individualism and power distances. The idea is that corruption tends to be higher in cultures that encourage individuals to prioritize loyalty towards one's social group above the individual itself (Rose-Ackerman, 1999), i.e. in cultures with lower rates of individualism. Another dimension of culture that influences the level of corruption is what Hofstede (2001) termed "power distances," or termed "hierarchy" by Schwartz $(1999,2004)$. A worker in a culture with large power distances prefers large distances between the people in power and himself. These societies end up being more hierarchical and also tend to be more corrupt. These two dimensions of culture are used here as instruments for corruption in cross-country regressions on gross domestic product (GDP) per capita.

However, these culture dimensions might be correlated with other factors that influence GDP per capita. This would render them invalid as instruments (the exclusion restrictions would not hold). Since there are two instruments, the overidentification (OID) test can be used to test this. In all regressions, this test accepts that corruption is the only channel through which these particular culture dimensions influence GDP per capita. While this is encouraging, it does not prove anything, since the OID test is a test of low power, meaning that it accepts "too many" wrong hypotheses (Wooldridge, 2002). Hence, whether the effect of corruption on economic prosperity can be estimated, hinges on whether it is possible to control for all relevant covariates. Note that it does not matter for the validity of the instruments that factors influencing culture have been omitted, as long as these factors do not influence GDP per capita. Hence, if one can control for everything with a bearing on GDP per capita, the exclusion restrictions hold. In order to choose these relevant controls, the framework of "deep determinants" of economic prosperity is relied upon (Acemoglu et al., 2001; Hall and Jones, 1999; Licht et al., 2007; Rodrik, 2004). The idea is that deep determinants of development such as institutions, geography, and culture affect proximate factors such as technological progress and investments in human and physical capital, which then determine the level of GDP per capita. Applied to the present paper; if the framework of deep determinants captures the entire variation in economic development, any link between culture and economic development can be accounted for, provided that one possesses measures of all these deep determinants. In other words; if institutions, geography, and culture exhaust the list of possible deep determinants, one is left only to find good measures of these dimensions.

In order to reduce the degrees of freedom in choosing these control variables, included are all measures of institutions and culture available in a large online dataset provided by the Quality of Government Institute, encompassing all central measures from the literature (Teorell et al., 2009).

Another concern, that one might have, is that the instruments could be influenced by the level of GDP per capita. However, this should not be a problem when using these particular culture measures, since they are from 1967 and 1973 (with an extension in 2001), whereas GDP and corruption are from 2006. Furthermore, Hofstede's culture measures are based on interviews of a group of people rather similar across countries, namely IBM workers. This makes the measures not so representative for a particular country's culture, but very suitable for value comparisons across countries, as they are rather independent of demographics, income, etc. Nevertheless, empirical evidence is 
provided showing that culture is, indeed, exogenous to the level of economic development. Specifically, an instrument is used for individualism provided by Licht et al. (2007); pronoun drop. The reasoning is that the language of less individualist cultures evolves to drop the pronoun (I, she, they, etc.), since the individual is less important compared with more individualist countries.

This study differs from Mauro's in one last aspect. By linking corruption to growth rates of GDP per capita, Mauro explains the transitional dynamics towards steady state. Instead, Hall and Jones (1999) stressed that the level of GDP per capita should be employed if the purpose is to explain the long run differences in economic performance (Acemoglu et al., 2001; Rodrik et al., 2004). As this paper analyses the level of GDP per capita, the conclusions thus concern long run differences and not short run dynamics.

\section{Framework: Deep Determinants of Economic Prosperity}

This paper follows a broad literature seeking the fundamental causes of long run development (Rodrik et al., 2004). According to neoclassical growth theory, crosscountry income differences arise from a combination of differences in the rates of technological progress and physical and human capital investment. More recently, authors have raised the deeper question: "Why is it that some countries do not improve their technology, invest more in physical capital, and accumulate more human capital?" (Hall and Jones, 1999). There must be some reasons underneath that prevent countries from improving the proximate causes of economic development. The literature has broadly agreed on three such reasons: institutions (corruption, contracting institutions, and property rights institutions) (Acemoglu et al., 2001; Hall and Jones, 1999), geography (Sachs, 2003), and culture (Guiso et al., 2006; Tabellini, 2010). ${ }^{1}$ This framework is consistent with a regression line of the form: ${ }^{2}$

$G D P C A P_{i}=\beta_{0}+\beta_{1} C O R R U P T_{i}+\beta_{2} G E O_{i}+\beta_{2} C U L T U R E_{i}+\beta_{4} I N S T_{i}+\varepsilon_{i}$,

where $\beta_{1}$ is the parameter of interest in the present paper. Institutions have been split into corruption, CORRUPT, and remaining institutions, INST. GDPCAP $P_{i}$ is real GDP per capita in country $i, G E O$ is a vector of geographical factors, and CULTURE is a vector of culture dimensions.

If institutions, geography, and culture span the entire set of deep determinants of economic prosperity, regressions of type (1) will explain the entire variation in GDP per capita across countries. Hence, in the perfect world, where we have perfect data, we would expect an $R^{2}$ of $100 \%$. This is obviously a rather naïve assumption, but in the empirical analysis an explanatory power of the model of around $80 \%$ is obtained. If the "deep determinants" framework is true, the deviation from $100 \%$ is simply due to measurement error.

\section{Data}

\section{GDP Per Capita}

GDP per capita is from Heston et al.'s (2009) Penn world Tables (PWT). Real GDP per capita is used from PWT version 6.3 (the measure called rgdpl2) in 2006. 2006 is not the most recent year, but the most recent year might be subject to more measurement error. 


\section{Corruption}

The measure of corruption used in the main regressions is control of corruption in 2006 (cci2006) by Kaufmann et al. (2009). The index runs from -2.5 to 2.5, where lower values indicate less control of corruption, meaning more corruption. This index includes various measures of corruption, which might reduce the scope for measurement error.

\section{Remaining Institutions}

The Quality of Governance (QOG) dataset by Teorell et al. (2009) provides a long list of measures of institutions, gathered from some of the most central research. Acemoglu and Johnson (2005) defined institutions as encompassing property rights institutions and contracting institutions. Some authors also included rule of law (Licht et al., 2007). Therefore, this paper includes all institutional measures from QOG, except measures of labor market institutions, which gives a total of 23 measures in addition to corruption (described in Web Appendix A1). ${ }^{3}$ As contracting institutions were not included in the QOG dataset, two measures of contracting institutions used by Acemoglu and Johnson (2005) have been added; "number of procedures" and "procedural complexity," also described in Web Appendix A1.

\section{Geography}

Regional dummies capture a large share of the variation in geography. The ones used here are by World Development Indicators: Sub-Saharan Africa (SSA), South Asia (SOA), East Asia \& Pacific (EAP), Latin America \& Caribbean (LAC), Middle East \& North Africa (MENA), North America (NA), and Europe \& Central Asia (ECA). The results are unchanged when using instead continent dummies. Other measures of geography: absolute latitude, landarea in $\mathrm{km}^{2}$, a dummy for whether the country is landlocked, the share of the total area that lies within the tropics, a dummy for whether some part of the country lies within the tropics, elevation (mean meters above sea level), mean distance to coast, mean distance to river, mean distance to coast or river.

\section{Hofstede Culture Measures}

The measures of culture that are used as instruments for corruption are from Hofstede (2001). ${ }^{4}$ Hofstede performed value surveys of a group of people, similar across countries, namely IBM employees. This makes his survey suitable for value comparisons across countries, as opposed to studies such as World Values Survey, which are more suitable for obtaining representative measures of culture within a country. From the value surveys, Hofstede developed a model that identifies five primary dimensions to differentiate cultures. The first is power distances (PDI) which is the degree to which inequality in the distribution of power is accepted and expected in a society. The second is individualism (IDV), the extent to which a society reinforces individual or collective achievement. The three remaining dimensions are described in Web Appendix A1. The value surveys of the IBM workers were performed in 1967 and 1973 with an extension in 2001 .

\section{Remaining Culture}

In addition to the Hofstede measures, 26 measures of culture were gathered from the QOG dataset. All religious, language, and colonial origin variables, which have been argued to be proxies for culture, were added. All are described in Web Appendix A1. 


\section{OLS Estimation}

Panel A of Table 1 provides ordinary least squares (OLS) estimates of equation (1), regressing 2006 real GDP per capita on corruption and the various deep determinants.

Table 1. OLS and IV (TSLS) Estimates of the Impact of Corruption on GDP Per Capita

\begin{tabular}{|c|c|c|c|c|c|c|c|c|c|}
\hline & (1) & (2) & (3) & (4) & (5) & (6) & (7) & (8) & $(9)^{a}$ \\
\hline \multicolumn{10}{|c|}{ Dependent variable: rgdpl22006 } \\
\hline Regional dummies & no & yes & yes & yes & yes & yes & yes & yes & no \\
\hline \multicolumn{10}{|l|}{ Panel A: OLS estimates } \\
\hline cci2006 & $\begin{array}{l}10.582^{* * * *} \\
(0.766)\end{array}$ & $\begin{array}{l}9.223^{* * * *} \\
(0.807)\end{array}$ & $\begin{array}{l}8.547 * * * \\
(0.901)\end{array}$ & $\begin{array}{l}11.182^{* * * *} \\
(0.982)\end{array}$ & $\begin{array}{l}10.119 * * * \\
(0.857)\end{array}$ & $\begin{array}{l}9.637 * * * \\
(0.993)\end{array}$ & $\begin{array}{l}11.062^{* * * *} \\
(1.147)\end{array}$ & $\begin{array}{l}9.644^{* * * *} \\
(0.950)\end{array}$ & $\begin{array}{l}10.238^{* * * *} \\
(0.567)\end{array}$ \\
\hline fh_rol & & & & $\begin{array}{c}-0.435^{*} \\
(0.233)\end{array}$ & & & $\begin{array}{l}-0.523 * * \\
(0.253)\end{array}$ & & \\
\hline logh_polcons & & & & $\begin{array}{l}-5.265 \\
(4.540)\end{array}$ & $\begin{array}{l}-8.811^{* *} \\
(3.933)\end{array}$ & & $\begin{array}{l}-4.856 \\
(4.477)\end{array}$ & $\begin{array}{l}-8.671^{* *} \\
(3.946)\end{array}$ & \\
\hline logproc_compl & & & & $\begin{array}{c}2.295 \\
(2.169)\end{array}$ & $\begin{array}{c}2.092 \\
(2.164)\end{array}$ & & $\begin{array}{c}2.741 \\
(2.397)\end{array}$ & $\begin{array}{c}2.493 \\
(2.386)\end{array}$ & \\
\hline logdistcr & & & $\begin{array}{l}-1.148 \\
(0.794)\end{array}$ & & & & $\begin{array}{l}-0.505 \\
(0.555)\end{array}$ & $\begin{array}{l}-0.309 \\
(0.545)\end{array}$ & \\
\hline logelev & & & $\begin{array}{l}-1.288 \\
(1.022)\end{array}$ & & & & $\begin{array}{l}-0.859 \\
(0.717)\end{array}$ & $\begin{array}{l}-0.901 \\
(0.745)\end{array}$ & \\
\hline lp_protmg80 & & & & & & $\begin{array}{c}-0.070^{*} \\
(0.036)\end{array}$ & $\begin{array}{l}-0.009 \\
(0.048)\end{array}$ & $\begin{array}{l}-0.003 \\
(0.046)\end{array}$ & \\
\hline Observations & 186 & 186 & 156 & 122 & 122 & 178 & 119 & 119 & 119 \\
\hline$R^{2}$ & 0.569 & 0.629 & 0.663 & 0.811 & 0.806 & 0.633 & 0.814 & 0.808 & 0.793 \\
\hline$F$-test $c c i 2006=9.223, p$ & 0.078 & 1.000 & 0.454 & 0.049 & 0.298 & 0.677 & 0.112 & 0.659 & 0.076 \\
\hline \multicolumn{10}{|c|}{ Panel B: TSLS estimates (corruption endogenous), second stage } \\
\hline cci2006 & $\begin{array}{l}10.760 * * * \\
(1.124)\end{array}$ & $\begin{array}{l}8.706 \text { *** } \\
(1.269)\end{array}$ & $\begin{array}{l}8.613 * * * \\
(1.363)\end{array}$ & $\begin{array}{l}10.480 * * * \\
(3.216)\end{array}$ & $\begin{array}{l}10.059 * * * \\
(1.563)\end{array}$ & $\begin{array}{l}9.969 * * * \\
(1.888)\end{array}$ & $\begin{array}{l}15.062^{* * *} \\
(5.239)\end{array}$ & $\begin{array}{l}11.436 * * * \\
(1.972)\end{array}$ & $\begin{array}{l}14.606^{* * * *} \\
(1.968)\end{array}$ \\
\hline fh_rol & & & & $\begin{array}{l}-0.115 \\
(0.665)\end{array}$ & & & $\begin{array}{l}-1.061 \\
(1.080)\end{array}$ & & \\
\hline logh_polcon 5 & & & & $\begin{array}{l}-9.545 \\
(6.752)\end{array}$ & $\begin{array}{c}-9.901 \\
(6.884)\end{array}$ & & $\begin{array}{l}-8.617 \\
(5.666)\end{array}$ & $\begin{array}{c}-12.346^{* *} \\
(6.056)\end{array}$ & \\
\hline logproc_compl & & & & $\begin{array}{c}4.072 \\
(3.273)\end{array}$ & $\begin{array}{c}3.835 \\
(2.763)\end{array}$ & & $\begin{array}{l}8.627^{* * *} \\
(4.056)\end{array}$ & $\begin{array}{l}7.115^{* * *} \\
(2.952)\end{array}$ & \\
\hline logdistcr & & & $\begin{array}{l}-1.476 \\
(1.267)\end{array}$ & & & & $\begin{array}{c}-0.172 \\
(1.098)\end{array}$ & $\begin{array}{c}0.511 \\
(0.757)\end{array}$ & \\
\hline logelev & & & $\begin{array}{l}-0.304 \\
(1.127)\end{array}$ & & & & $\begin{array}{l}-1.980^{*} \\
(1.112)\end{array}$ & $\begin{array}{l}-1.902 \\
(1.167)\end{array}$ & \\
\hline lp_protmg80 & & & & & & $\begin{array}{c}-0.067 \\
(0.067)\end{array}$ & $\begin{array}{l}-0.075 \\
(0.092)\end{array}$ & $\begin{array}{l}-0.050 \\
(0.070)\end{array}$ & \\
\hline Observations & 79 & 79 & 75 & 71 & 71 & 78 & 69 & 69 & 69 \\
\hline$R$-squared & 0.669 & 0.714 & 0.726 & 0.811 & 0.810 & 0.724 & 0.816 & 0.819 & 0.800 \\
\hline Kleibergen-Paap $F$ & $68.11+1+$ & $48.12+\uparrow \dagger$ & $48.37+1 \dagger$ & 7.595 & $23.63+1+$ & $30.99+1+$ & 3.314 & $16.50+\uparrow$ & $17.02+\dagger$ \\
\hline Cragg-Donald F & $51.16+t+$ & $30.77+1 \dagger$ & $36.80+1 \dagger$ & 5.330 & $15.69+\dagger$ & $20.65+1+$ & 3.511 & $11.90+\uparrow$ & $13.82+\uparrow$ \\
\hline OID $p$-value & 0.117 & 0.613 & 0.899 & 0.367 & 0.367 & 0.701 & 0.350 & 0.270 & 0.248 \\
\hline$F$-test $c c i 2006=8.706, p$ & 0.068 & 1.000 & 0.946 & 0.581 & 0.387 & 0.504 & 0.225 & 0.166 & 0.003 \\
\hline Robust Hausman test, $p$ & 0.725 & 0.348 & 0.561 & 0.710 & 0.584 & 0.723 & 0.786 & 0.938 & 0.551 \\
\hline
\end{tabular}

Notes: OLS and second stage TSLS estimates. Dependent variable is real GDP per capita in 2006 from PWT. Robust standard errors in parentheses. In all columns of Panel B, corruption is instrumented with Hofstede's power distances (PDI) and individualism (IDV). Constant included in all regressions. $* * * * * *$ indicate significance at the $10 \%, 5 \%$, and $1 \%$ level, respectively. $\dagger, \uparrow \dagger, \uparrow \dagger \dagger$ indicate TSLS size distortions of a maximum of $20 \%, 15 \%$, and $10 \%$, respectively.

${ }^{a}$ Instead of the control variables included in column (7), the corresponding principal components are included. The principal components are based on the principal components analysis performed in Web Appendix A2. 


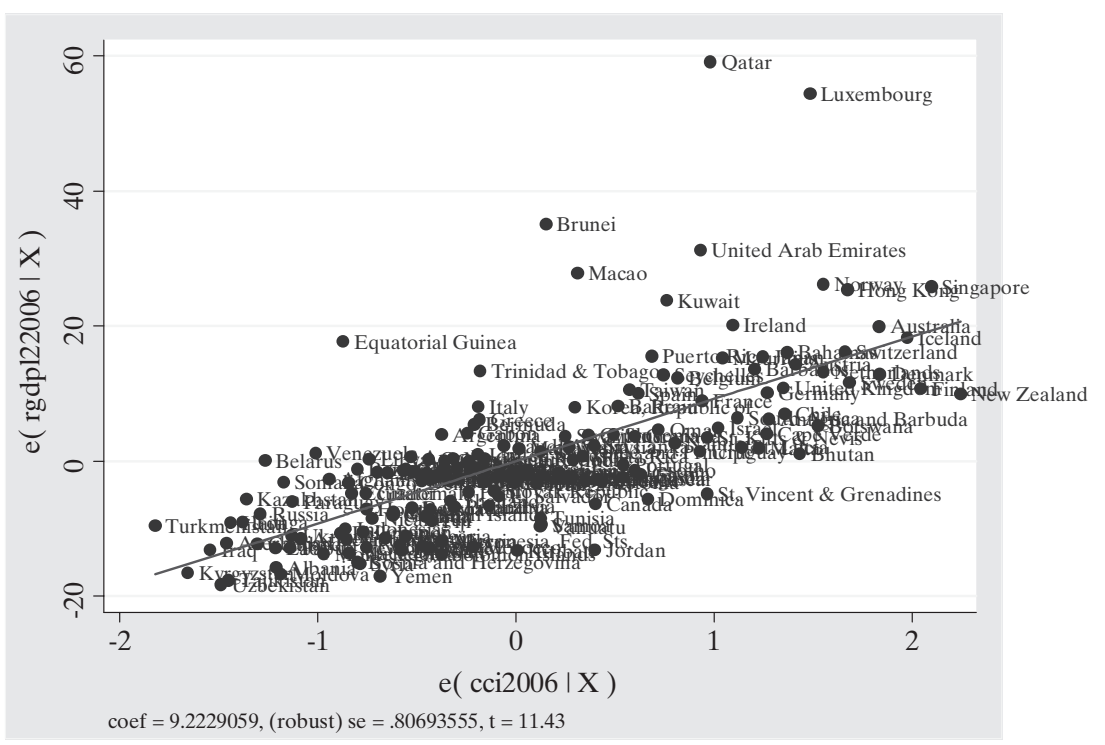

Figure 1. OLS Estimation of Column (2), Panel A, Table 1

In column (1), control of corruption is the only explanatory variable, exerting a significant and positive impact on GDP per capita, meaning that the impact of corruption is negative. Obviously, this simple correlation is biased. First of all; omitted factors potentially influence both corruption and GDP. A way to eliminate this particular bias is to use the deep determinants framework to include all factors that affect GDP per capita. Column (2) includes regional dummies, which should pick up a large share of the variation in GDP due to geographic differences. Corruption exerts a significant and negative impact on GDP per capita; taking the OLS estimate of column (2) at face value, a one unit increase in corruption (standard error 0.99) reduces real GDP per capita by US $\$ 9223$. The added-variable plot corresponding to column (2) is shown in Figure 1 . No single group of countries seems to be driving the result. ${ }^{5}$

Another way to account for omitted variables is two-stage least-squares (TSLS) estimation, which also eliminates bias owing to reverse causality. TSLS is performed in panel B of Table 1, which will be commented on in section 5 below.

Columns (3)-(6) of Panel A include the remainder of the three groups of deep determinants as control variables: geography, institutions, and culture. There are numerous measures of these three determinants, and studies like the present are dependent on the particular list of control variables. For instance, it is always possible to find some measure of institutions that does not "kill" the corruption effect, if this is what the purpose is. To limit the degrees of freedom, this paper has taken all measures of institutions and culture from the large online dataset gathered by the Quality of Governance Institute (QOG), they have been included one by one, and the measure yielding the highest explanatory power to the model has been chosen.

Unfortunately, the QOG dataset does not include geographical measures. Most of the geographical variation is already accounted for by the regional dummies, but nevertheless nine additional geographical covariates have been included one by one in the column (2) regression.

Another choice increasing the degrees of freedom of the empirical researcher is the choice between taking logs or not. To reduce the degrees of freedom, a choice between 
taking logs or not has been made by using the solution with the highest explanatory power. ${ }^{6}$

\section{Geography}

The top two geographic measures yielding highest explanatory power when included one by one in column (2) are also the only two significant measures; log of distance to coast or river (logdistcr) and log of elevation above sea level (logelev). These are included in column (3). The estimate of corruption remains significant at the $1 \%$ level, and the size of the estimate is statistically unchanged compared to column (2) (the same result prevails when including them one by one).

\section{Institutions}

Similarly for the measures of institutions, the 25 institutional measures have been included one by one in regression (2), taking logs whenever the explanatory power was higher. ${ }^{7}$ Within each of the three categories of institutions (property rights institutions, rule of law, and contracting institutions), the measure was picked leaving the model with the highest explanatory power. Column (4) includes these three dimensions of institutions: The measure of property rights institutions providing highest $R^{2}$ was Henisz' (2000) political constraints measure, logh_polcon5, higher scores indicating more political constraint. The rule of law measure that gives highest explanatory power to the model was a measure by Freedom House, fh_rol, higher scores indicating more rule of law. ${ }^{8}$ None of the six measures of contracting institutions turned out significant. Nonetheless, to complete the model in line with Acemoglu and Johnson (2005), included in column (4) was the measure of contracting institutions yielding the highest explanatory power, procedural complexity, logproc_compl, higher scores meaning more procedural complexity. ${ }^{9}$ Corruption is still significant at the $1 \%$ level, and the estimate increases above the column (2) estimate. The column (4) results might suffer from problems of multicollinearity; the rule of law measure, $f h \_r o l$, is highly correlated with both corruption (corr 0.77 ) and the property rights measure, logh_polcon5 (corr 0.73). Column (5) excludes the rule of law measure, including only property rights institutions and contracting institutions in line with the analysis by Acemoglu and Johnson (2005). The explanatory power of the model does not fall much. Excluding instead property rights institutions and keeping rule of law reduces the explanatory power even less (not shown), which indicates that maybe the rule of law dimension is a better fit than property rights institutions. In column (9), the multicollinearity problem is dealt with by using principal components analysis (described below).

\section{Culture}

The QOG dataset includes numerous measures of culture, mostly from the World Values Survey. All of them have not included, but 31 measures were found of various religious affiliations, ethnic fractionalization, and also some measures from World Values Surveys that measure similar culture dimensions as the Hofstede measures. Only one of all these measures had a significant impact on GDP per capita at the $10 \%$ level when included in the column (2) regression; fraction of Protestants in 1980, lp_protmg $80 .{ }^{10}$ Column (6) includes fraction of Protestants, leaving the estimate of corruption and the level of significance unchanged. 
Columns (7) and (8) include all deep determinants, excluding rule of law in column (8) to reduce the potential multicollinearity issue. Corruption remains negative and significant at the $1 \%$ level.

The main purpose of this part of the analysis is to remove as much as possible of the variation in GDP per capita caused by the deep determinants. This will both reduce bias caused by omitted variables, but will also increase the validity of the instruments in the next part of the analysis. Therefore, the aim is to get rid of the multicollinearity problem in another way than excluding variables. In Web Appendix A2 a principal component analysis (pca) is performed to replace the control variables by their principal components. ${ }^{11}$ In short, combinations of the control variables (so-called principal components) areidentified that explain as large a share of the variation in GDP per capita as possible and theya areincluded into the analysis in column (9) (corresponds to column (11) of Table A3 in Web Appendix A2). This method is useful, as the particular estimate of the control variables is of no interest here-only the estimate on corruption. Note that the estimate of corruption becomes more precise than in any other specification and is now higher than the column (2) estimate at the $10 \%$ level. The increased estimate is not due to the smaller sample; when reducing the sample to the 119 observations, the column (2) estimate drops to 8.703. Hence, it seems that the omitted factors in the column (2) regression are driving down the corruption estimate, making corruption seem less severe.

Note that the $R^{2}$ of columns (7), (8), and (9) reaches as high as $81 \%$, which is high for cross-country regressions.

\section{Identification}

Obviously, the estimates in Panel A of Table 1 may be biased by endogeneity. The level of GDP per capita might influence corruption and richer countries have more resources to combat corruption (e.g. Gundlach and Paldam, 2009). Alternatively GDP could have a similar effect on any of the other dimensions of institutions, which will also bias the estimate of corruption.

This paper has attempted to solve the endogeneity problem exploiting the idea that corruption is affected by deeply rooted cultural values (Rose-Ackerman, 1999; Treisman, 2000; Licht et al., 2007). Two dimensions of culture in particular seem to be impacting the tendency to be corrupt—dimensions concerning individualism and hierarchy.

\section{Intrumental Variable (IV) Strategy}

Individualism distinguishes between collectivist societies, where people attach great importance to their social networks, and individualist societies, where the individuals' rights and responsibilities are in focus (Hofstede, 2001; Schwartz, 1999). A collectivist orientated culture values tightly knit relations in which people expect their social group to look after them in exchange for unquestioning loyalty. When allocating resources, a public official favors his own social group in return for a share of the benefits. In relation to this, Rose-Ackerman (1999) observed that (p. 98) "He [the public official] may do this not only because he cares for them [the social group], but also because they care about him and will be less likely than strangers to reveal the corrupt deal or renege on the agreement. The interdependency of utilities reduces the risks to both participants." Decisions made in more collectivist societies are, ceteris paribus, subject to less 
questioning from people within the same social network as the particular decision maker and the risk of getting caught is lower (Licht et al., 2007).

Several other authors have noted a relationship between individualism and corruption (Husted, 1999 for an overview). Hooper (1995) linked the tendency to favor one's ingroup to corruption in Spain. Banfield (1958) saw a connection between the "amoral familiarism" (favoritism for family members) of a small village in Italy and the tendency for its public office holders to accept bribes.

The other culture dimension, Hofstede's "power distance" measure, focuses on the degree to which inequality in the distribution of power is accepted and expected in a society. Hofstede notes that larger power distances in a society mean fewer checks and balances on the use of power, and thereby more corruption. He underlines this idea by a credited statement by Lord Acton, a 19th century British historian: "Power tends to corrupt, and absolute power corrupts absolutely." 12 In societies, where power is expected and accepted to be distributed unequally, people tend to be less critical toward decisions made by authorities. This reduces transparency and means that authorities in high power distance societies are faced with lower costs of corruption-in terms of the risk of getting caught-compared with societies where equal distribution of power is expected and where people in power are kept accountable by a critical populace. Takyi-Asiedu (1993) has linked power distances to corruption in sub-Saharan Africa. He found that in high power distance countries, "scandals involving people in authority are, almost always, covered up as long as they remain in power." Treisman (2000) argued that in places where more hierarchical religions prevail, critical positioning towards people in power is rarer.

Based on this reasoning, Hofstede's two culture measures individualism (IDV) and power distances (PDI) are used as instruments for corruption in equation (1). Figure 2 provides the simple scatterplots of CORRUPT vs IDV and PDI, showing the expected relationships: Countries with more individualism or smaller power distances tend to be less corrupt.

\section{Estimation}

Panel B of Table 1 shows the TSLS estimates of the same regressions as in panel A. The difference between the two panels is that corruption in Panel B is instrumented with the Hofstede culture dimensions of power distance and individualism.

As a test of whether the instruments are weak, the Kleibergen-Paap $F$ statistic is used, which is the heteroskedasticity robust generalization of the Cragg-Donald $F$ statistic (which is again equivalent to the first stage $F$ statistic in the case of one endogenous regressor). There has still not been generated critical values for the Kleibergen-Paap $F$ statistic, so it is custom to use the critical values for the Cragg-Donald $F$ statistic, available from Stock and Yogo (2005). For comparison, the Cragg-Donald $\mathrm{F}$ statistic is also provided in the tables. It is indicated whether the weak instrument test statistic is above or below the critical values provided by Stock and Yogo (2005). Specifically, the TSLS maximal size distortionis used, which provides the most binding critical values, compared with TSLS bias. Stock and Yogo (2005) provide maximum size distortions of 10\%, 15\%, 20\%, and $25 \%$.

In column (1), where corruption is the only explanatory variable, the KleibergenPaap $F$ statistic equals 68, which is well above the highest critical value of 19.93. Hence, IDV and PDI are strong instruments for corruption. 

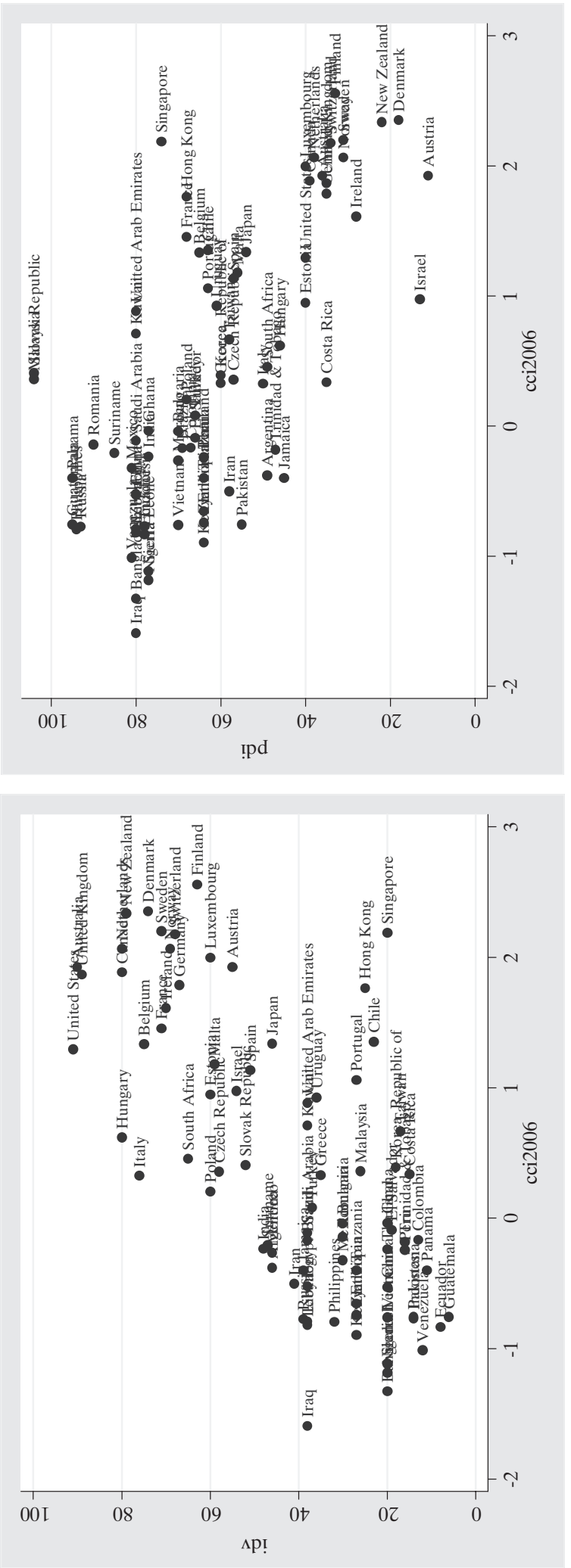

ป

질

ลิ

5

$\stackrel{2}{\circ}$

ป

2

$\frac{8}{8}$

$\frac{a}{2}$

है

这
$\vdots$
0
0 
Panel B of Table 1 also provides the $p$-value of the OID test, which tests whether corruption is the only channel through which the instruments influence GDP per capita. This is a test of low power and it should not be relied upon independently. Interestingly, in column (1) we can only accept at the $12 \%$ level that the two culture dimensions only influence GDP per capita through corruption. This is a very low level of acceptance and it supports the suspicion that there might exist other channels through which these dimensions of culture influence GDP per capita or that there might be some excluded factors influencing both culture and GDP. This points to the importance of including other deep determinants of economic productivity. Indeed, the OID $p$-value increases to $61.3 \%$ in column (2), where the regional dummies are included, indicating that the problem of exclusion restrictions might be solved by just including these dummies. Again, the test has low power, and we continue by operating within the framework of deep determinants.

Adding other geography variables in column (3) does not alter the size or level of significance of the corruption estimate compared to the column (2) estimate. Adding the remaining dimensions of institutions in column (4) makes the instruments weak, inflating the standard errors and potentially biasing the estimates. Limited maximum likelihood (LIML) estimation is more robust to weak instruments. When using LIML estimation instead (not shown), the instruments become fairly strong (critical value of $15 \%$ LIML size distortion is 5.33) and the corruption estimate is 10.45 (standard error 3.35), significant and unchanged compared with column (2).

Again, the column (4) estimate might be biased because of multicollinearity between rule of law and both corruption and property rights institutions. When excluding the rule of law measure in column (5), the culture instruments are again strong and the estimate of corruption is unchanged compared to column (2).

The instruments remain strong in column (6), where the culture measure, fraction of Protestants, is included and the estimate of corruption is unchanged compared to the column (2) regression.

Columns (7) and (8) include all deep determinants simultaneously. The instruments remain fairly strong in column (8), where rule of law is excluded. The corruption estimate remains significant at the $1 \%$ level and statistically not different from the estimate in column (2), albeit it is numerically somewhat higher.

Again, use is made of principal component analysis to produce principal components that span the entire set of control variables, solving the multicollinearity problem and increasing the precision of the corruption estimate. The analysis is performed in Web Appendix A2 and the significant principal components are included in column (9) of Table 1 . The instruments are fairly strong and the corruption estimate increases above the column (2) estimate. When running the column (2) regression on the column (9) sample, the corruption estimate is unchanged at 8.729. Hence the increase is not due to sample differences.

The heteroskedasticity robust Hausman test cannot reject that the estimate of corruption is the same as that produced by OLS. That is, there does not seem to be a problem of endogeneity.

To sum up, corruption exerts a statistically significant and negative impact on productivity levels across countries in the samples studied. The effect is economically significant. Taking the lowest estimate (column (3), Panel A, Table 1), a one unit reduction in the level of corruption increases the level of GDP per capita by US\$8547. Within this sample of 156 countries, the control of corruption index runs from -1.83 in Somalia to 2.56 in Finland. Hence, a one unit reduction of corruption amounts to $22.8 \%$ of the entire interval. On the same sample, GDP per capita runs from a low of US $\$ 369$ 
in Liberia to a peak of US\$77,242 in Qatar. Hence, an increase of US\$ 8547 amounts to $11.1 \%$ of the interval. This means that reducing corruption in a country with a fifth of what is possible can increase this country's GDP per capita by more than $10 \%$. Taking instead the highest corruption estimate from column (9) of Table 1, panel B, a one unit reduction in the level of corruption increases the level of GDP per capita by US $\$ 14,606$. Within this sample of 69 countries, the control of corruption index runs from -1.32 in Bangladesh to 2.56 in Finland. Hence, a one unit reduction of corruption amounts to $25.8 \%$ of the interval. On the same sample, GDP per capita runs from a low of US\$887 in Tanzania to a peak of US\$49,391 in the United Arab Emirates. Hence, an increase of US\$14,606 amounts to $30.1 \%$ of the interval. While being large, the effect is not implausibly large.

\section{Robustness: Other Endogenous Regressors}

The remaining dimensions of institutions could impose other problems of endogeneity, biasing the estimate of interest. In Table 2 therefore, instruments are included for the remaining dimensions of institutions; property rights institutions, rule of law, and contracting institutions. The instruments meant for corruption remain PDI and IDV throughout. Since the instruments for the remaining institutions are somewhat weaker, LIML estimation is used instead of TSLS. ${ }^{13}$

Property rights institutions Column (1) of Table 2 includes property rights institutions and uses Albouy's (2012) corrected version of Acemoglu et al.'s (2001) instrument for property rights institutions, settler mortality, together with urbanization rates from 1500, also suggested by Acemoglu et al. (2001). The number of observations drops to 27 and the instruments become extremely weak, producing huge standard errors and making all the estimates unreliable. In column (2) the same instruments are kept, but another measure of property rights institutions is used, namely the preferred measure used by Acemoglu and Johnson (2005); constraint on executive ( $\left.p \_x c o n s t\right)$. This measure produced the second highest explanatory power of the model when the measures of property rights institutions were included one by one in the column (2) regressions of Table 1 . The instruments become strong. The critical value for the weak instrument test provided by Stock and Yogo (2005) for two endogenous variables and four instruments based on LIML size distortions of a maximum of $10 \%$ is $4.7<9.6$ (Kleibergen-Paap $F$ statistic). The estimate of corruption remains highly significant and not numerically different from the OLS estimate in column (2) of Table 1 . The estimate of property rights institutions is insignificant.

Rule of law Column (3) includes the rule of law measure, fh_rol, and introduces as instrument another culture dimension identified by Hofstede, uncertainty avoidance index (UAI). The UAI focuses on the level of tolerance for uncertainty and ambiguity within a society. It indicates to what extent people feel comfortable in unstructured situations. Unstructured situations are novel, unknown, surprising, different from usual. Uncertainty avoiding cultures try to minimize the possibility of such situations by strict laws and rules, safety, and security measures. Therefore, it is expectedthat countries with high UAI would have better rule of law institutions, which proves to be the case. The instruments are fairly strong (above the $15 \%$ size distortion critical value) and the estimate of corruption remains unchanged. The estimate of rule of law is insignificant.

Contracting institutions Column (4) includes the last dimension of institutions, contracting institutions, instrumented with a dummy capturing French legal origin, 


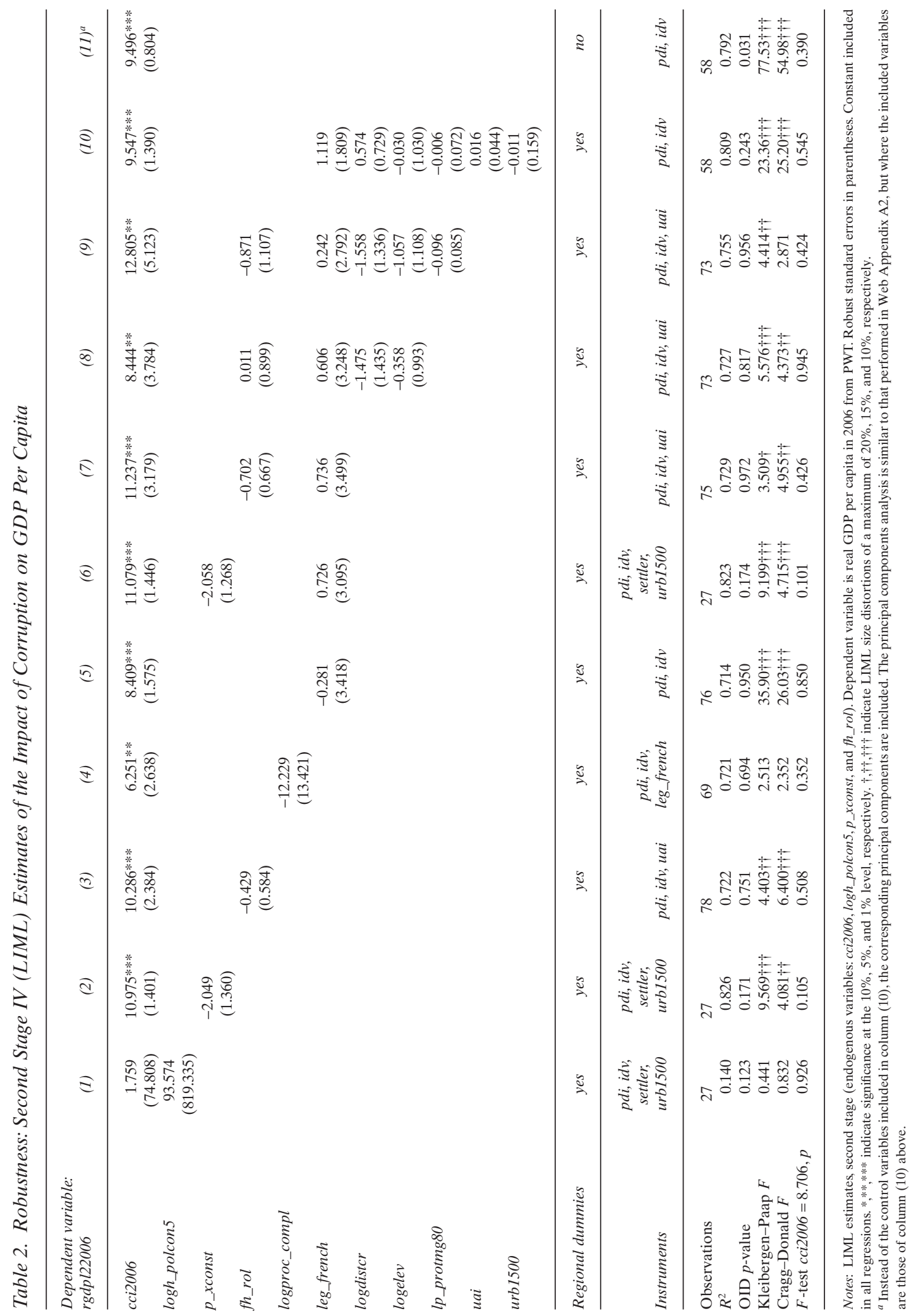


suggested by Acemoglu and Johnson (2005). The instruments become weak and the estimates unreliable (the same is the case using English legal origin etc.). Therefore the instrument for contracting institutions, French legal origin, is included instead directly into the regressions in column (5). The idea is that French legal origin captures at least some of the variation in contracting institutions. ${ }^{14}$ This makes the instruments for corruption strong and the estimate of corruption is unchanged compared to column (2) in panel B of Table 1 .

Columns (6) and (7) include the property rights institutions and rule of law measures, respectively together with the French legal origin dummy, producing strong instruments (not so strong for rule of law) and unchanged estimate of corruption. Adding geography to the pool of controls produces weak instruments in the regression with property rights institutions (not shown), but strong instruments in the regression with rule of law (column 8) and statistically unchanged estimate of corruption (albeit it falls somewhat in absolute value). Column (9) adds the last deep determinant, culture, which produces fairly strong instruments. Column (10) includes the instruments for property rights institutions and rule of law directly into the regression, producing strong instruments and unchanged estimate of corruption. ${ }^{15}$ Column (11) includes the three significant principal components produced from a principal components analysis of the control variables in column (10). The estimate of corruption becomes again more precise and is not different from the Table 1, column (2) estimate.

\section{Robustness: Instrument Exogeneity}

The Hofstede dimensions of culture that are used as instruments for corruption, IDV and PDI, are measured 30 years before corruption and GDP, and it is therefore not possible for either corruption or GDP to have an effect on the instruments. Further, since Hofstede constructed the measures from a survey of a very similar group of people, IBM workers, the measures should be independent of demographic differences etc. across countries. Nevertheless, one may still worry that some omitted factors influence GDP and culture. There are many factors influencing individuals' inherited cultural beliefs, but omitting these will only bias the results if these factors also influence GDP per capita. Using the deep determinants framework, it was hoped to be able to include all factors with a bearing on GDP. If this was successful, there is no reason to worry about instrument endogeneity, but if the deep determinants framework is wrong or if the measures are systematically biased, factors could have been omitted that influence both culture and GDP, invalidating the instruments.

It can be testest empirically whether IDV is exogenous in relation to GDP per capita, since there is an instrument for IDV. Licht et al. (2007) argued that less individualist cultures have a tendency to drop the pronoun (I, you, he, she, etc.), since the individual is less important in these cultures and therefore it does not matter whether it was he, she or I who did this and that. They document that a dummy equal to one if the country has dropped the pronoun is a strong instrument for IDV. Table 3 shows the results from the TSLS estimation of IDV on GDP per capita, using pronoun drop as an instrument for IDV. No control variables are included in column (1), and pronoun drop is a strong instrument for IDV ( $F=62>16.38$, the $10 \%$ critical value with one instrument). The Robust Hausman test cannot reject that IDV is exogenous in relation to GDP per capita.

It seems unlikely that pronoun drop influences GDP per capita through other channels than culture, but just to make sure, the exogenous deep determinants of GDP per capita are included in columns (3) and (4). IDV remains exogenous in relation to GDP per capita. 
Table 3. Robustness: Testing Instrument Exogeneity (IV)

(1)

(2)

(3)

(4)

Second stage TSLS estimates, dependent variable: rgdpl22006

\begin{tabular}{|c|c|c|c|c|}
\hline$i d v$ & $\begin{array}{l}0.381 \text { *** } \\
(0.068)\end{array}$ & $\begin{array}{l}0.371 \text { *** } \\
(0.082)\end{array}$ & $\begin{array}{l}0.389 \text { *** } \\
(0.099)\end{array}$ & $\begin{array}{l}0.330^{* * * *} \\
(0.116)\end{array}$ \\
\hline logdistcr & & & $\begin{array}{c}-1.758 * \\
(0.980)\end{array}$ & $\begin{array}{c}-1.924 * * \\
(0.952)\end{array}$ \\
\hline logelev & & & $\begin{array}{c}-1.216 \\
(2.057)\end{array}$ & $\begin{array}{c}-1.173 \\
(2.067)\end{array}$ \\
\hline lp_protmg 80 & & & & $\begin{array}{c}0.059 \\
(0.067)\end{array}$ \\
\hline Regional dummies $^{a}$ & no & yes & yes & yes \\
\hline $\begin{array}{l}\text { First stage estimate of pr } \\
\text { pronoun }\end{array}$ & $\begin{array}{c}\text { dependent } \mathrm{v} \\
-35.913^{* * * *} \\
(4.558)\end{array}$ & $\begin{array}{l}\text { e: } i d v \\
-21.666^{* * *} \\
(7.094)\end{array}$ & $\begin{array}{l}-18.942 * * \\
(7.150)\end{array}$ & $\begin{array}{l}-20.502 * * \\
(7.739)\end{array}$ \\
\hline \multicolumn{5}{|c|}{ OLS estimate of $i d v$, corresponding to TSLS regressions } \\
\hline$i d v$ & $\begin{array}{l}0.352 * * * \\
(0.043)\end{array}$ & $\begin{array}{l}0.333^{* * *} \\
(0.049)\end{array}$ & $\begin{array}{l}0.356 \text { *** } \\
(0.050)\end{array}$ & $\begin{array}{l}0.332 \text { *** } \\
(0.052)\end{array}$ \\
\hline Observations & 69 & 69 & 66 & 66 \\
\hline$R^{2}$ & 0.375 & 0.413 & 0.550 & 0.560 \\
\hline Kleibergen-Paap $F$ & $62.08+\uparrow \dagger$ & $17.8+\dagger \dagger$ & $15.68+\dagger$ & $9.858 \dagger \dagger$ \\
\hline Cragg-Donald $F$ & $74.44 \dagger+\dagger$ & $39.88+\dagger \dagger$ & $31.29+\dagger \dagger$ & $19.38+\dagger \dagger$ \\
\hline Robust Hausman test, $p$ & 0.537 & 0.562 & 0.667 & 0.981 \\
\hline
\end{tabular}

Notes: TSLS estimates (endogenous variable: $i d v$ ). Dependent variable is real GDP per capita in 2006 from PWT. Robust standard errors in parentheses. Constant included in all regressions. ***,*** indicate significance at the $10 \%, 5 \%$, and $1 \%$ level, respectively. $\uparrow, \uparrow \uparrow, \uparrow \dagger \dagger$ indicate TSLS size distortions of a maximum of $20 \%, 15 \%$, and $10 \%$, respectively.

${ }^{a}$ Owing to singleton dummies, the regional dummies are gathered into larger groupings: SOA+EAP, SSA+MENA, NA+LAC, and ECA.

Unfortunately, there is no instrument for PDI. Instead, as a last check of instrument exogeneity, Table 4 shows that IDV and PDI explain a significant share of the variation in GDP per capita (columns 1-3), but that the impact of IDV and PDI goes away once corruption is controlled for (columns 4-6). this is taken as indicating that the impact of culture works only through corruption. The same pattern emerges when including IDV and PDI separately (not shown).

\section{Conclusion}

This paper provides an estimate of the impact of corruption on economic productivity levels. The motivation for doing so is that the estimate from Mauro's (1995) study is still the estimate referred to in the literature, despite the well-known econometric shortcomings of the analysis. This attempt at overcoming these shortcomings starts with providing new strong instruments for corruption.

The hypothesis is that more hierarchical cultures that focus more on loyalty towards one's social group than the individual's own responsibility, are more prone to become corrupt compared with more individualist and egalitarian cultures. This is supported by the empirics. Further, these dimensions prove to be strong instruments for corruption in the regressions on GDP per capita. 
Table 4. Robustness: Testing Instrument Exogeneity (OLS)

\begin{tabular}{lcccccc}
\hline $\begin{array}{l}\text { Dependent variable: } \\
\text { rgdpl22006 }\end{array}$ & $(1)$ & $(2)$ & $(3)$ & $(4)$ & $(5)$ & $(6)$ \\
\hline cci2006 & & & & $11.327^{* * * *}$ & $10.793^{* * * *}$ & $\begin{array}{c}10.693^{* * * *} \\
(1.451)\end{array}$ \\
idv & & & & $(1.792)$ & $(2.345)$ \\
& $0.276^{* * *}$ & $0.112^{*}$ & $0.165^{* * *}$ & 0.046 & -0.053 & -0.017 \\
pdi & $(0.053)$ & $(0.056)$ & $(0.059)$ & $(0.051)$ & $(0.061)$ & $(0.070)$ \\
& $-0.169^{* * *}$ & $-0.197^{* * *}$ & $-0.165^{* * *}$ & 0.075 & 0.028 & 0.007 \\
logdistcr & $(0.063)$ & $(0.052)$ & $(0.060)$ & $(0.056)$ & $(0.053)$ & $(0.054)$ \\
& & & -2.215 & & & -0.796 \\
logelev & & & $(1.341)$ & & & $(1.096)$ \\
& & & 0.001 & & & -1.236 \\
lp_protmg80 & & & $(1.632)$ & & & -0.090 \\
& & & -0.010 & & & $(0.082)$ \\
Regional dummies & $n o$ & yes & yes & $n o$ & yes & yes \\
Observations & 79 & 79 & 75 & 79 & 79 & 75 \\
$R^{2}$ & 0.374 & 0.518 & 0.591 & 0.676 & 0.723 & 0.739 \\
\hline
\end{tabular}

Notes: OLS estimates. Dependent variable is real GDP per capita in 2006 from PWT. Robust standard errors in parentheses. Constant included in all regressions. $* * *, * * *$ indicate significance at the $10 \%, 5 \%$, and $1 \%$ level, respectively.

However, one could imagine that these dimensions are correlated with other deep factors that influence productivity levels. Therefore, the reliability of the estimates hinges on inclusion of additional deep determinants of GDP per capita; geography and the remaining dimensions of both institutions and culture. To reduce the degrees of freedom arising when choosing between the numerous measures of these deep determinants, this paper is restricted by including all measures from an online dataset by Teorell et al. (2009) encompassing variables from the central research in the field. After including these factors, the instruments remain strong and the impact of corruption on GDP per capita remains statistically and economically significant and negative.

\section{References}

Acemoglu, Daron and Simon Johnson, "Unbundling Institutions," Journal of Political Economy 113 (2005):949-95.

Acemoglu, Daron, Simon Johnson, and James A. Robinson, "The Colonial Origins of Comparative Development: An Empirical Investigation," American Economic Review 91 (2001):1369_ 401.

Albouy, David Y., "The Colonial Origins of Comparative Development: An Investigation of the Settler Mortality Data," American Economic Review, forthcoming (2012).

Banfield, Edward C., The Moral Basis of a Backward Society, New York: The Free Press (1958). de Vaal, Albert and Wouter Ebben, "Institutions and the Relation between Corruption and Economic Growth," Review of Development Economics 15 (2011):108-23.

Easterly, William and Ross Levine, "Africa's Growth Tragedy: Policies and Ethnic Divisions," Quarterly Journal of Economics 112 (1997):1203-50.

Flores-Lagunes, Alfonso, "Finite Sample Evidence of IV Estimators Under Weak Instruments," Journal of Applied Econometrics 22 (2007):677-94. 
Gallup, John Luke, Jeffrey D. Sachs, and Andrew D. Mellinger, "Geography and Economic Development," International Regional Science Review 22 (1999):179-232.

Guiso, Luigi, Paola Sapienza, and Luigi Zingales, "Does Culture Affect Economic Outcomes?" Journal of Economic Perspective 20 (2006):23-48.

Gundlach, Erich and Martin Paldam, "The Transition of Corruption: From Poverty to Honesty," Economic Letters 103 (2009):146-48.

Hall, Robert E. and Charles I. Jones, "Why do some Countries Produce so much More Output Per Worker than Others?" Quarterly Journal of Economics 114 (1999):83-116.

Henisz, Witold J., "The Institutional Environment for Economic Growth," Economics and Politics 12 (2000):1-31.

Heston, Alan, Robert Summers, and Bettina Aten, Penn World Table Version 6.3, Center for International Comparisons of Production, Income and Prices at the University of Pennsylvania, Philadelphia (2009).

Hofstede, Geert, Culture's Consequences: Comparing Values, Behaviors, Institutions, and Organizations Across Nations (2nd ed.), Beverly Hills, CA: Sage (2001).

Hooper, John, The New Spaniards, London: Penguin Books (1995).

Husted, Bryan W., "Wealth, Culture and Corruption," Journal of International Business Studies 30 (1999):339-59.

Kaufmann, Daniel, Aart Kraay, and Massimo Mastruzzi, "Governance Matters VIII: Governance Indicators for 1996-2008,” World Bank Policy Research, Washington, DC, June (2009).

La Porta, Rafael, Florenzio Lopez de Silanes, Andrew Shleifer, and Robert W. Vishny, "The Quality of Government," Journal of Law, Economics, and Organization 15 (1999):222-79.

Leff, Nathaniel H., "Economic Development Through Bureaucratic Corruption," American Behavioral Scientist 8 (1964):8-14.

Licht, Amir N., Chanan Goldschmidt, and Shalom H. Schwartz, "Culture Rules: The Foundations of the Rule of Law and Other Norms of Governance," Journal of Comparative Economics 35 (2007):659-88.

Mauro, Paulo, “Corruption and Growth," Quarterly Journal of Economics 110 (1995):681712.

Rodrik, Dani, Arvind Subramanian, and Francesco Trebbi, "Institutions Rule: The Primacy of Institutions Over Geography and Integration in Economic Development," Journal of Economic Growth 9 (2004):131-65.

Rose-Ackerman, Susan, Corruption and Government: Causes, Consequences, and Reform, Cambridge: Cambridge University Press (1999).

Sachs, Jeffrey, "Institutions Don't Rule: Direct Effects of Geography on Per Capita Income," NBER working paper 9490 (2003).

Schwartz, Shalom H., "Cultural Value Differences: Some Implications for Work," Applied Psychology: An International Review 48 (1999):23-47.

_ "Mapping and Interpreting Cultural Differences Around the World," in H. Vinken, J. Soeters and P. Ester (eds), Comparing Cultures, Leiden: Brill (2004):43-73.

Stock, James H. and Motohiro Yogo, "Testing for Weak Instruments in Linear IV Regression," in D.W.K. Andrews and J.H. Stock (eds), Identification and Inference for Econometric Models: Essays in Honor of Thomas Rothenberg, Cambridge: Cambridge University Press (2005).

Tabellini, Guido, "Culture and Institutions: Economic Development in the Regions of Europe," Journal of the European Economic Association 8 (2010):677-716.

Takyi-Asiedu, Stephen, "Some Socio-cultural Factors Retarding Entrepreneurial Activity in sub-Saharan Africa," Journal of Business Venturing 8 (1993):91-98.

Teorell, Jan, Nicholas Charron, Marcus Samanni, Sören Holmberg, and Bo Rothstein, "The Quality of Government Dataset," version 17 June 09, University of Gothenburg: The Quality of Government Institute, available at http://www.qog.pol.gu.se (2009).

Treisman, Daniel, "The Causes of Corruption: A Cross-national Study," Journal of Public Economics 76 (2000):399-457.

Wooldridge, Jeffrey M., Econometric Analysis of Cross Section and Panel Data, Cambridge, MA: The MIT Press (2002). 


\section{Notes}

1. Some authors argue that trade should also belong with these deep determinants. However, trade can be viewed as belonging to the more proximate factors, being itself affected by both institutions, geography, and culture.

2. de Vaal and Ebben (2011) showed in a theoretical model that the impact of corruption on growth depends on the institutional framework. This speaks for including an interaction term between corruption and institutions, which could form a basis for future research.

3. Web Appendices A1 and A2 are available on the author's webpage.

4. See also his webpage: www.geert-hofstede.org

5. Removing the two countries Qatar and Luxembourg reduces the corruption point estimate from 9.2 to 8.4 , which is not a statistically significant difference.

6. Of course, logs were not taken where it does not make sense, e.g. indexes and dummies.

7. Seven of the 25 measures turned out to exert a significant impact on GDP per capita: va2006, logbti_prp, logbti_rol,fh_rol,logh_polcon3, logh_polcon5, and p_xconst (see Web Appendix A1). Including all measures gives an estimate of corruption of 9.7 with a $t$-statistic of 5. 6. That is, no change of the results. One could use principal components analysis and insert the principal components into the regression instead of the variables one by one. However, the problem is that the variables do not have enough observations in common.

8. The estimate of rule of law is negative, but the raw correlation between GDP and rule of law is positive as one would expect. The negative estimate might reflect that countries that already have good institutions (in terms of low corruption, low political constraints, and low procedural complexities) might not benefit from more rule of law.

9. If instead the measure of contracting institutions from column (4) is excluded, the estimate of corruption increases from 11.2 to 11.6.

10. Additional measures of culture turned out significant when excluding the regional dummies, though. This finding underlines the importance of regional dummies and indicates that these culture measures capture nothing more than regional differences.

11. The author thanks an anonymous referee for suggesting this.

12. Lord Acton made his statement in a letter to Bishop Mandell Creighton dated 5 April 1887.

13. A Monte Carlo study done by Flores-Lagunes (2007) suggests that LIML does at least as well as alternatives. LIML is less precise than TSLS, but also less biased.

14. When only regressing contracting institutions on GDP and instrumenting with French legal origin, the instrument is strong, suggesting that countries with French legal origin indeed have more procedural complexities.

15. Note that settler mortality is not included. Including this variable in column (10) reduces the number of observations to 26 and produces weak instruments. 